\title{
Alternative Approaches Applied to Inductively Coupled Plasma Techniques: Multi-Flow and Two-Flow Calibration
}

\author{
Raquel C. Machado, ${ }^{\oplus a}$ Ana Beatriz S. Silva, ${ }^{\oplus a, b}$ Daniel F. Andrade, ${ }^{a}$ \\ Fernanda C. Pinheiro, ${ }^{a}$ Charles B. Williams, ${ }^{c}$ George L. Donati, ${ }^{\circledR d}$ \\ Ana Rita A. Nogueira ${ }^{\circledR b}$ and Edenir R. Pereira-Filho ${ }^{\circledR *, a}$
}

${ }^{a}$ Grupo de Análise Instrumental Aplicada, Departamento de Química, Universidade Federal de São Carlos, 13565-905 São Carlos-SP, Brazil

${ }^{b}$ Embrapa Pecuária Sudeste, 13560-970 São Carlos-SP, Brazil

${ }^{c}$ Department of Chemistry, Davidson College, 28035 Davidson, NC, USA

${ }^{d}$ Department of Chemistry, Wake Forest University, 27109 Winston-Salem, NC, USA

\begin{abstract}
Multi-flow calibration (MFC) is based on monitoring the analytical signal from a single calibration standard solution at several different nebulization gas flow rates $(\mathrm{Q})$, which normalizes plasma conditions and minimizes matrix effects. In the present study, MFC was evaluated, for the first time, applied to inductively coupled plasma optical emission spectrometry (ICP OES) and inductively coupled plasma mass spectrometry (ICP-MS) to analyze different and complexmatrix samples. $\mathrm{Al}, \mathrm{As}, \mathrm{Cd}, \mathrm{Cr}, \mathrm{Cu}, \mathrm{Mn}, \mathrm{Pb}$, and $\mathrm{Zn}$ were determined by ICP OES, while As, $\mathrm{Cd}, \mathrm{Co}, \mathrm{Cu}, \mathrm{Hg}, \mathrm{Mo}, \mathrm{Mn}, \mathrm{Ni}, \mathrm{Se}, \mathrm{Sb}, \mathrm{Pb}$, and $\mathrm{V}$ were determined by ICP-MS. MFC results were compared with those obtained using external standard calibration (EC) for both techniques and in all cases, MFC showed equal or superior accuracy (recoveries between 80-120\%) compared to $\mathrm{EC}$, and lower relative standard deviation (RSDs $\leq 10 \%$ ). Several tests were also performed using only two nebulization gas flows to build linear models for calibration (called two-flow calibration, TFC) and the accurate results (recoveries ranged from 80 to $110 \%$ for ICP OES and from 81 to $102 \%$ for ICP-MS) suggests that this strategy can be also applied, resulting in a method with high sample throughput.
\end{abstract}

Keywords: nebulization gas, calibration strategy, matrix effects, ICP OES, ICP-MS

\section{Introduction}

Argon plasma-based techniques such as inductively coupled plasma optical emission spectrometry (ICP OES) and inductively coupled plasma mass spectrometry (ICP-MS) are considered state-of-the-art for elemental determination. These techniques are versatile and may be successfully employed for a wide range of matrices. ${ }^{1,2}$ Despite its advantages (e.g., sensitivity, multi-elemental capabilities, wide linear range of detection, and versatility), some drawbacks still exist such as spectral and non-spectral interferences that can compromise the reliability of results and the analytical performance., 3

Although common for both of these spectroanalytical techniques, spectral interferences are more pronounced in ICP-MS determinations. Isobaric interference, which

*e-mail: erpf@ufscar.br may be due to a non-analyte isotope or a polyatomic ion, is caused by overlap of the analytical signal with that of an interfering species signals at the same mass-to-charge ratio $(\mathrm{m} / \mathrm{z})$ in a relatively low-resolution quadrupole-based system. In such cases, an overestimated value is found when compared to the real analyte concentration. ${ }^{3}$ For ICP OES, spectral interferences can be avoided by choosing an interference-free analytical wavelength. On the other hand, for ICP-MS, many strategies have been described to minimize spectral interferences, such as mathematical correction, cold plasma conditions, systems based on a collision/reaction cell (CRC) or collision/reaction interface (CRI), and the use of a high-resolution sector field ICP-MS (HR-SF-ICP-MS). ${ }^{3,5-7}$

Non-spectral interferences are also common in both ICP-based techniques but are still more pronounced in ICP-MS when compared to ICP OES. These interferences are usually related to matrix effects, which are caused by 
sample constituents such as carbon and easily ionizable elements (EIE's) and by transport effects due to viscosity of some solvents (organic and inorganic, for example). ${ }^{8-10}$ Depending on the concentration and nature of these interfering components, sample transport efficiency, aerosol generation, and both excitation and ionization processes may be affected. Both enhancement and suppression of the analytical signal may be observed due to non-spectral interferences, which may simply be corrected by employing calibration strategies such as standard additions (SA), internal standardization (IS), or external standard calibration with matrix matching. ${ }^{11,12}$ Recently, new calibration methods such as standard dilution analysis (SDA), ${ }^{13}$ multi-energy calibration (MEC), ${ }^{14}$ multi-isotope calibration (MICal), ${ }^{15}$ multispecies calibration (MSC) ${ }^{16}$ and one-point standard addition (OP SA $)^{17,18}$ have been proposed to overcome matrix effects without the limitations of the traditional SA and IS.

Another newly proposed method is the multi-flow calibration (MFC), which was described and applied to microwave-induced plasma optical emission spectrometry (MIP OES). In MFC, the analytical signal is recorded from a single calibration standard and sample solutions at multiple nebulization gas flow rates $(\mathrm{Q})$ and at only one wavelength. ${ }^{19}$ Thus, several levels of analytical signal are obtained and used to build a linear model useful for calibration. The linear model describing the relationship between the analytical signal recorded for the calibration standard ( $x$-axis) and the sample ( $y$-axis) solutions is used to determine the unknown analyte concentration $\left(\mathrm{C}_{\text {Sample }}\right)$. The slope of the MFC plot and the concentration of the analyte in the calibration standard, $\mathrm{C}_{\text {standard }}$, are then used to determine $\mathrm{C}_{\text {Sample }}$, as shown in equation 1.

$\mathrm{C}_{\text {Sample }}=$ slope $\times \mathrm{C}_{\text {standard }}$

In addition to its simplicity, another advantage of the MFC method is that, even though no matrix matching strategy is employed, less pronounced matrix effects can be obtained. As multiple nebulization gas flow rates are employed, the sample and calibration standard solutions are exposed to different plasma conditions, which results in a plasma normalizing effect that contributes to improved accuracy. ${ }^{19}$

Considering the potential of the MFC method, first described and applied to MIP OES, the goal of the present study is to evaluate, for the first time, its application to argon plasma-based techniques such as ICP OES and ICP-MS. In addition to evaluating the MFC method applied to different techniques, some improvements were introduced, and the possibility of employing only two nebulization gas flow rate conditions (2-Q) for analysis was tested. The 2-Q approach referred here to as two-flow calibration (TFC). Different matrices (polymer, plant tissue, bovine liver, and soil) were analyzed, and the MFC results for multiple analytes were compared with those from the traditional external standard calibration (EC).

\section{Experimental}

Instrumentation

Experiments were performed using an iCAP7000 series ICP OES (Thermo Fisher Scientific, Waltham, MA, USA) operated in robust conditions and axial viewing mode, and an Agilent 7800 Quadrupole ICP-MS (Agilent Technologies, Tokyo, JHS, Japan) operated in high matrix introduction (HMI) mode, with either no gas or He $(99.999 \%$, White Martins-Praxair, Sertãozinho, SP, Brazil) in the collision/ reaction cell. In HMI mode, the aerosol leaving the spray chamber is diluted with Ar before reaching the plasma. The total gas flow rate is composed of $60 \%$ of HMI gas and $40 \%$ of carrier gas. As example, the first nebulization gas flow rate (Q) used for MFC, $0.40 \mathrm{~L} \mathrm{~min}^{-1}$, has HMI and carrier gases flowing at 0.24 and $0.16 \mathrm{~L} \mathrm{~min}^{-1}$, respectively. The following nebulizer gas flow rates employed in MFC were: 0.3, 0.4, 0.5, 0.6 and $0.7 \mathrm{~L} \mathrm{~min}^{-1}$ for ICP OES, and 0.4, 0.6, $0.8,1.0,1.2$ and $1.4 \mathrm{~L} \mathrm{~min}^{-1}$ for ICP-MS. In the case of TFC, 0.30 and $0.60 \mathrm{~L} \mathrm{~min}^{-1}$ and 0.4 and $0.8 \mathrm{~L} \mathrm{~min}^{-1}$ were used for ICP OES and ICP-MS, respectively. For comparison, EC was performed using $Q$ values of 0.7 and $1.0 \mathrm{~L} \mathrm{~min}^{-1}$ $\mathrm{Ar}$ for ICP OES and ICP-MS, respectively. Al, $\mathrm{As}, \mathrm{Cd}$, $\mathrm{Cr}, \mathrm{Cu}, \mathrm{Mn}, \mathrm{Pb}$, and $\mathrm{Zn}$ were determined by ICP OES, while $\mathrm{As}, \mathrm{Co}, \mathrm{Cu}, \mathrm{Hg}, \mathrm{Mo}, \mathrm{Mn}, \mathrm{Ni}, \mathrm{Se}, \mathrm{Sb}, \mathrm{Pb}$, and $\mathrm{V}$ were determined by ICP-MS. The calibration curve ranges were 0.01-2.5 $\mathrm{mg} \mathrm{L}^{-1}$ for ICP OES and 0.05-50 $\mu \mathrm{g} \mathrm{L}^{-1}$ for ICP-MS. Plasma operating conditions and additional instrumental parameters used in ICP OES and ICP-MS are listed in Table 1.

A microwave-assisted digestion system (UltraWAVE ${ }^{\mathrm{TM}}$, Milestone, Italy) equipped with a single reaction chamber (SRC) was used to digest the samples prior to ICP analysis. It consists of a stainless steel high-pressure SRC covered with a 900-mL modified poly-tetra-fluoro-ethylene (TFM) liner. Nitrogen (99.9\%, White Martins-Praxair, Sertãozinho, SP, Brazil) was used to pressurize the system to $40 \mathrm{bar}$ before running the heating program.

Reagents, analytical solutions, and reference samples

All working solutions were prepared using deionized water (18.2 $\mathrm{M} \Omega \mathrm{cm}$, Milli-Q, Millipore, Bedford, MA, USA). Microwave-assisted acid digestion was performed 
Table 1. Operating parameters and accessories used in ICP OES and ICP-MS

\begin{tabular}{|c|c|c|}
\hline Instrument parameter & ICP OES & ICP-MS \\
\hline RF applied power / $\mathrm{kW}$ & 1.15 & 1.55 \\
\hline Plasma gas flow rate / $\left(\mathrm{L} \mathrm{min}^{-1}\right)$ & 12 & 15 \\
\hline Auxiliary gas flow rate / $\left(\mathrm{L} \mathrm{min}^{-1}\right)$ & 0.50 & 1.00 \\
\hline Sampling depth / mm & NA & 8.0 \\
\hline $\begin{array}{l}\text { He flow rate in collision cell / } \\
\left(\mathrm{mL} \mathrm{min} \mathrm{min}^{-1}\right)\end{array}$ & NA & 4.5 \\
\hline Integration time $/ \mathrm{s}$ & 15 & 3.0 \\
\hline Nebulizer & concentric & Mira-Mist \\
\hline Spray chamber & cyclonic & $\begin{array}{l}\text { Scott type-double } \\
\text { pass }\end{array}$ \\
\hline Number of replicate & 3 & 3 \\
\hline Analyte & Emission line / $\mathrm{nm}$ & Isotope $(\mathrm{m} / \mathrm{z})$ \\
\hline $\mathrm{Al}$ & 167.079 & NA \\
\hline As & 189.042 & 75 \\
\hline $\mathrm{Cd}$ & 228.802 & 114 \\
\hline Co & NA & 59 \\
\hline $\mathrm{Cr}$ & 267.716 & NA \\
\hline $\mathrm{Cu}$ & 327.396 & 65 \\
\hline $\mathrm{Hg}$ & NA & 202 \\
\hline Mo & NA & 98 \\
\hline $\mathrm{Mn}$ & 259.373 & 55 \\
\hline $\mathrm{Ni}$ & NA & 58 \\
\hline $\mathrm{Pb}$ & 216.999 & 208 \\
\hline $\mathrm{Sb}$ & NA & 121 \\
\hline $\mathrm{Se}$ & NA & 78 \\
\hline V & NA & 51 \\
\hline $\mathrm{Zn}$ & 213.856 & NA \\
\hline
\end{tabular}

RF: radiofrequency; ICP OES: inductively coupled plasma optical emission spectrometry; ICP-MS: inductively coupled plasma mass spectrometry; NA: not applicable once the element was not determined by this technique.

using $\mathrm{H}_{2} \mathrm{O}_{2}\left(30 \% \mathrm{v} \mathrm{v} \mathrm{v}^{-1}\right.$, Synth, Diadema, SP, Brazil) and high-purity $\mathrm{HNO}_{3}\left(65 \% \mathrm{v} \mathrm{v}^{-1}\right.$, Neon, Suzano, SP, Brazil), previously purified using a sub-boiling distillation system
(Distillacid, Berghof, Germany). Standard solutions were prepared by appropriate dilution of single-element stock solutions containing $1000 \mathrm{mg} \mathrm{L}^{-1}$ of the analyte (Merck, Darmstadt, Germany).

A set of three certified reference materials (CRMs), ERM-EC680K (polyethylene, low level-European reference material, ERM, Geel, Belgium), ERM-EC681K (polyethylene, high level-ERM), and NIST 1570a (trace elements in spinach leaves-National Institute of Standards and Technology, NIST, Gaithersburg, USA), and two reference materials (RMs), RM-Agro E3001a (bovine liver, Embrapa) ${ }^{20}$ and RM-Agro E2002a (soil, Embrapa) ${ }^{21}$ were used to evaluate the accuracy of both MFC and TFC methods. Table 2 shows the analytes determined in each RM/CRM and the corresponding technique used for each determination. Each technique was applied based on the analyte concentrations present in each RM/CRM.

\section{Sample preparation and MFC/TFC evaluation}

All reference materials were decomposed in triplicate using $200 \mathrm{mg}$ of sample. A $5 \mathrm{~mL}$ aliquot of $65 \% \mathrm{v} \mathrm{v}^{-1}$ $\mathrm{HNO}_{3}$ was used to digest ERM-EC680K, ERM-EC681K, and RM-Agro E2002a. For NIST 1570a and RM-Agro E3001a, $5 \mathrm{~mL}$ of $2 \mathrm{~mol} \mathrm{~L}^{-1} \mathrm{HNO}_{3}$ and $2 \mathrm{~mL}$ of $\mathrm{H}_{2} \mathrm{O}_{2}$ were used for matrix decomposition. A 5-position rack with quartz vials (maximum reagent volume of $30 \mathrm{~mL}$ ) was used for polyethylene digestion (ERM-EC680K and ERM-EC681K), and a 15-position rack with poly-tetrafluoro-ethylene (PTFE)/TFM vials (maximum reagent volume of $10 \mathrm{~mL}$ ) was used for digesting the other reference materials. The heating cycles employed for microwaveassisted acid digestion were carried out under $1500 \mathrm{~W}$ of applied power and maximum temperature and pressure of $230{ }^{\circ} \mathrm{C}$ and 100 bar, respectively. The digested solutions were transferred to polypropylene tubes, and the volume was adjusted to $25 \mathrm{~mL}$ with deionized water.

Both MFC and TFC methods require a single calibration standard solution. The concentration of the analyte in this solution was evaluated considering the following sample/

Table 2. Elements determined by ICP OES and ICP-MS in the CRMs and RMs analyzed

\begin{tabular}{lcc}
\hline Material & ICP OES & ICP-MS \\
\hline ERM-EC680K (polyethylene, low level) & $\mathrm{NA}$ & $\mathrm{As}, \mathrm{Cd}, \mathrm{Hg}, \mathrm{Pb}, \mathrm{Sb}$ \\
ERM-EC681K (polyethylene, high level) & $\mathrm{As}, \mathrm{Cd}, \mathrm{Hg}, \mathrm{Pb}$ & $\mathrm{NA}$ \\
NIST 1570a (spinach leaves) & $\mathrm{Al}, \mathrm{Mn}, \mathrm{Zn}$ & $\mathrm{As}, \mathrm{Cd}, \mathrm{Co}, \mathrm{Cu}, \mathrm{Ni}, \mathrm{Se}, \mathrm{V}$ \\
RM-Agro E3001a (bovine liver) & $\mathrm{NA}$ & $\mathrm{Cd}, \mathrm{Co}, \mathrm{Mn}, \mathrm{Mo}, \mathrm{Se}$ \\
RM-Agro E2002a (soil) & $\mathrm{As}, \mathrm{Cd}, \mathrm{Cr}, \mathrm{Cu}, \mathrm{Pb}$ & $\mathrm{NA}$ \\
\hline
\end{tabular}

ICP OES: inductively coupled plasma optical emission spectrometry; ICP-MS: inductively coupled plasma mass spectrometry; NA: not applicable once the RM/CRMs were not analyzed by this technique. 
standard concentration ratios: 1:0.5, 1:1 and 1:2. The analysis was carried out by running the calibration standard and sample solutions separately and monitoring the instrument response in each case at multiple nebulization gas flow rates. Univariate linear models were obtained by plotting the analytical signal for the sample solution on the $y$-axis $v s$. analytical signal for the calibration standard solution on the $x$-axis. ${ }^{19}$

\section{Results and Discussion}

\section{MFC application to ICP OES and ICP-MS}

Due to the physical and chemical differences between samples and calibration standard solutions, EC may not be the most effective strategy for applications involving complex matrices and spectroanalytical techniques.,12 Considering some of the recently described calibration approaches to compensate for matrix effects in ICP OES and ICP-MS, MFC is the only one that allows the use of a single calibration standard, with no matrix matching involved. ${ }^{19}$ Nevertheless, it is still capable of correcting for some matrix effects because it exposes the sample and calibration standard solution to different plasma conditions, which has a normalizing effect able of minimizing signal bias. In MFC, both the calibration standard and the sample solutions are subject to the same changes due to induced variations in nebulization. Exposed to such changes, differences in the matrix between standard and samples become less pronounced, which can then be used to minimize matrix effects. ${ }^{19}$

Typical MFC plots are shown in Figure 1 for As, Cd and $\mathrm{Pb}$ determined by ICP OES (Figures $1 \mathrm{a}, 1 \mathrm{~b}$ and $1 \mathrm{c}$ ) in polymer CRM, using five nebulization gas flow rates, and for ${ }^{114} \mathrm{Cd},{ }^{59} \mathrm{Co}$ and ${ }^{51} \mathrm{~V}$ determined by ICP-MS (Figures $1 \mathrm{~d}$, 1e, and 1f) in spinach leaves CRM (NIST 1570a), using six nebulization gas flow rates to build the linear models. It is important to observe in Figure 1 that the models presented satisfactory linearities, which is also evident by determination coefficient values, $\mathrm{R}^{2}$, higher than 0.99 in all cases.

\section{Analytical performance of ICP OES and ICP-MS}

For EC, limits of detection (LOD) and quantification (LOQ) were calculated, according to IUPAC's recommendations, ${ }^{22}$ as three (LOD) and ten-fold (LOQ) the standard deviation of 10 measurements of the blank solution divided by the slope of the calibration curve. For ICP OES, however, the LOD calculation was based on the concept of background equivalent concentration (BEC). In this case, BEC was obtained from a $0.1 \mathrm{mg} \mathrm{L}^{-1}$ standard solution
$\left(\mathrm{BEC}=\mathrm{I}_{\text {blank }} \times \mathrm{C}_{\mathrm{A}} / \mathrm{I}_{\mathrm{A}}\right.$, where $\mathrm{I}_{\text {blank }}$ : analytical signal intensity for the blank, $\mathrm{C}_{\mathrm{A}}$ : analyte concentration in the standard, and $\mathrm{I}_{\mathrm{A}}$ : net analytical signal intensity for the standard), and the LOD was calculated as $\mathrm{LOD}=\left(3 \times \mathrm{BEC} \times \mathrm{RSD}_{\text {blank }}\right) / 100$, where $\mathrm{RSD}_{\text {blank }}$ is the relative standard deviation obtained from ten measurements of the blank.

For MFC in both ICP OES and ICP-MS, LOD and LOQ were calculated based on three and ten-fold the standard deviation of the estimated analyte concentration observed for a blank solution $\left(1 \% \mathrm{v} \mathrm{v}^{-1} \mathrm{HNO}_{3}, \mathrm{n}=10\right) .{ }^{19}$ Analytical performance parameters for $\mathrm{Al}, \mathrm{As}, \mathrm{Cd}, \mathrm{Cr}, \mathrm{Cu}, \mathrm{Hg}, \mathrm{Mn}, \mathrm{Pb}$ and $\mathrm{Zn}$ determined by ICP OES, and for $\mathrm{As}, \mathrm{Cd}, \mathrm{Co}, \mathrm{Cu}$, $\mathrm{Mo}, \mathrm{Mn}, \mathrm{Ni}, \mathrm{Se}, \mathrm{Sb}, \mathrm{Pb}$ and $\mathrm{V}$ in CRMs digests determined by ICP-MS using EC or MFC are shown in Table 3.

In ICP OES, LOQs obtained for MFC were higher than those calculated for EC, except for As. It is important to point out that higher MFC LOQs can be related to higher background signals observed at different Q conditions. ${ }^{19}$ This can be demonstrated by the relative standard deviation $\left(\mathrm{RSD}_{\text {blank }}\right)$ values calculated for each analyte in the blank solution, which ranged from 33 to $61 \%$. On the other hand, for ICP-MS the LOQs obtained for $\mathrm{Co}, \mathrm{Cu}, \mathrm{Hg}, \mathrm{Mo}, \mathrm{Ni}$, $\mathrm{Pb}$, and $\mathrm{V}$ using MFC were lower than those observed for $\mathrm{EC}$, which point out that for most isotopes the changes in $\mathrm{Q}$ values do not affect the background signals significatively. For the other elements, the LOQ values were very similar to those obtained with EC. The determination coefficient values, $\mathrm{R}^{2}$, obtained for MFC were expressed as a range, as a different analytical curve was used for each reference material replicate. Values in the 0.9778-0.9999 range were observed for all elements.

Similar to other calibration methods, MFC is unable to correct for spectral interferences. Thus, for ICP-MS, an octopole reaction system (ORS) was used with He in collision mode for correction of spectral interferences. Only when using this strategy, quantitative recoveries were obtained for ${ }^{75} \mathrm{As}^{+}$and ${ }^{58} \mathrm{Ni}^{+}$, probably due to signal bias caused by isobaric polyatomic species such as ${ }^{40} \mathrm{Ar}^{35} \mathrm{Cl}^{+}$ and ${ }^{23} \mathrm{Na}^{35} \mathrm{Cl}^{+}$. These interfering species may be especially abundant while analyzing high $\mathrm{Cl}$-containing samples, such as polymers.

Sample dilution is usually required in ICP-MS determinations to keep the level of total dissolved solids (TDS) below $0.1 \% \mathrm{~m} / \mathrm{v}^{23}$ Some instruments are equipped with an aerosol dilution system to overcome the limitations associated with such requirement. For the instrument used in the present study, it is called high matrix introduction (HMI). The HMI introduces a flow of Ar between the spray chamber and the torch, providing conditions for minimum dilution of digests (TDS around $3 \% \mathrm{~m} / \mathrm{v}$ ). ${ }^{23,24}$ Thus, considering the low certificated concentration values 

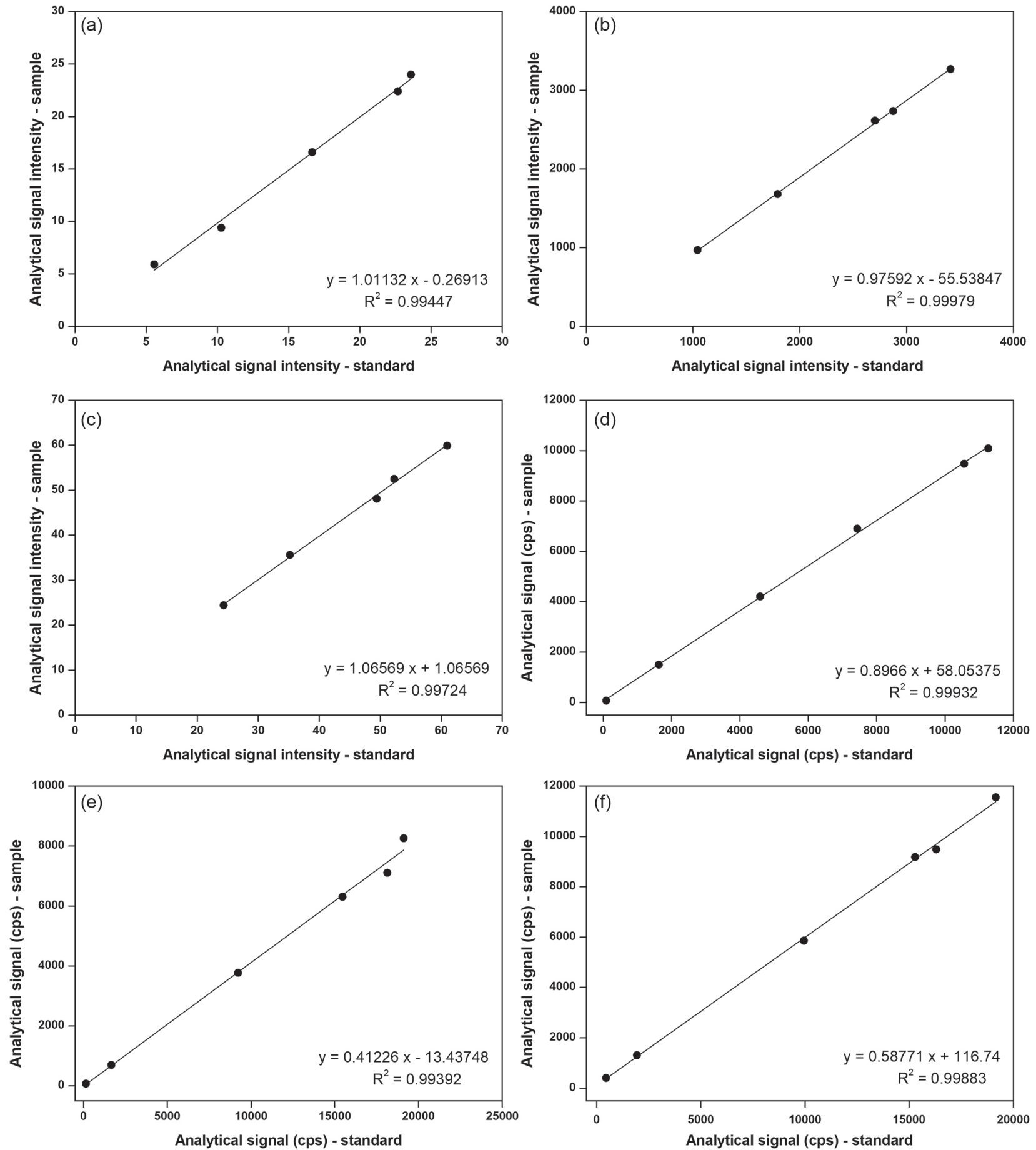

Figure 1. Multi-flow linear models considering the analytes concentration in the calibration standard solution as sample/standard ratio $1: 1$ for determination of (a) As, (b) $\mathrm{Cd}$ and (c) $\mathrm{Pb}$ in polymer CRM (ERM-EC681K) using ICP OES, and (d) ${ }^{114} \mathrm{Cd}$, (e) ${ }^{59} \mathrm{Co}$ and (f) ${ }^{51} \mathrm{~V}$ in spinach leaves CRM (NIST 1570a) using ICP-MS.

for As and Se in spinach leaves, the HMI mode was applied to reduce the dilution (10-fold less) before the analysis. As a consequence, the LOQs obtained using HMI and EC were nearly 14 and 5 -fold lower than using standard mode for As and Se, respectively. For MFC, the LOQs were nearly 33 and 4-fold lower using HMI than the standard mode for the same analytes (Table 3 ).

\section{Accuracy of the calibration method}

Taking into account the wide range of analyte concentrations in the different samples, the concentration of the calibration standard solution was evaluated to optimize the MFC application. The following sample/ standard concentration ratios were studied: 1:0.5, 1:1, and 
Table 3. Analytical performance parameters for the elements determined in the CRMs/RMs spinach leaves, soil, and polymer digests by ICP OES and in the CRMs/RMs spinach leaves, bovine liver, and polymer by ICP-MS using EC and MFC

\begin{tabular}{|c|c|c|c|c|c|c|c|c|c|}
\hline \multirow{3}{*}{ Analyte } & \multicolumn{4}{|c|}{ ICP OES } & \multicolumn{5}{|c|}{ ICP-MS } \\
\hline & \multicolumn{2}{|c|}{$\mathrm{EC}$} & \multicolumn{2}{|c|}{ MFC } & \multirow{2}{*}{$\begin{array}{l}\text { Acquisition } \\
\text { mode }\end{array}$} & \multicolumn{2}{|c|}{$\mathrm{EC}$} & \multicolumn{2}{|c|}{ MFC } \\
\hline & $\begin{array}{c}\mathrm{LOQ} / \\
\left(\mathrm{mg} \mathrm{kg}^{-1}\right)\end{array}$ & $\mathrm{R}^{2}$ & $\begin{array}{c}\text { LOQ / } \\
\left(\mathrm{mg} \mathrm{kg}^{-1}\right)\end{array}$ & $\mathrm{R}^{2}$ range & & $\begin{array}{c}\mathrm{LOQ} / \\
\left(\mathrm{mg} \mathrm{kg}^{-1}\right)\end{array}$ & $\mathrm{R}^{2}$ & $\begin{array}{c}\text { LOQ / } \\
\left(\mathrm{mg} \mathrm{kg}^{-1}\right)\end{array}$ & $\mathrm{R}^{2}$ range \\
\hline $\mathrm{Al}$ & 0.4 & 0.9989 & 2 & 0.9968-0.9998 & NA & NA & NA & NA & NA \\
\hline $\mathrm{Cd}$ & 0.08 & 0.9999 & 0.1 & 0.9936-0.9998 & no gas & 0.02 & 0.9995 & 0.01 & 0.9814-0.9999 \\
\hline Co & NA & NA & NA & NA & no gas & 0.01 & 0.9994 & 0.005 & 0.9909-0.9998 \\
\hline $\mathrm{Cr}$ & 0.2 & 0.9999 & 0.4 & 0.9996-0.9998 & NA & NA & NA & NA & NA \\
\hline $\mathrm{Cu}$ & 0.04 & 0.9999 & 2 & 0.9998 & no gas & 0.1 & 0.9996 & 0.08 & 0.9920-0.9998 \\
\hline $\mathrm{Hg}$ & NA & NA & NA & NA & no gas & 1.5 & 0.9996 & 0.3 & 0.9953-0.9989 \\
\hline Mo & NA & NA & NA & NA & no gas & 0.09 & 0.9995 & 0.04 & 0.9984-0.9999 \\
\hline $\mathrm{Mn}$ & 0.02 & 0.9999 & 0.2 & 0.9968-0.9970 & no gas & 0.04 & 0.9994 & 0.04 & 0.9989-0.9995 \\
\hline $\mathrm{Ni}$ & NA & NA & NA & NA & $\mathrm{He}$ & 0.09 & 0.9998 & 0.05 & 0.9964-0.9991 \\
\hline $\mathrm{Pb}$ & 2.0 & 0.9999 & 5 & $0.9778-0.9815$ & no gas & 0.2 & 0.9994 & 0.09 & 0.9955-0.9995 \\
\hline $\mathrm{Sb}$ & NA & NA & NA & NA & no gas & 0.03 & 0.9997 & 0.04 & 0.9979-0.9990 \\
\hline $\mathrm{V}$ & NA & NA & NA & NA & no gas & 0.02 & 0.9995 & 0.01 & $0.9968-0.9992$ \\
\hline $\mathrm{Zn}$ & 0.06 & 0.9999 & 0.3 & $0.9957-9968$ & NA & NA & NA & NA & NA \\
\hline \multirow{2}{*}{$\mathrm{As}^{\mathrm{a}}$} & \multirow{2}{*}{4} & \multirow{2}{*}{0.9999} & \multirow{2}{*}{3} & \multirow{2}{*}{ 0.9911-0.9985 } & $\mathrm{He}$ & 0.07 & 0.9996 & 0.3 & $0.9809-0.9978$ \\
\hline & & & & & $\mathrm{He} / \mathrm{HMI}$ & 0.005 & 0.9990 & 0.009 & 0.9889-0.9988 \\
\hline \multirow{2}{*}{$\mathrm{Se}^{\mathrm{a}}$} & \multirow{2}{*}{ NA } & \multirow{2}{*}{ NA } & \multirow{2}{*}{ NA } & \multirow{2}{*}{ NA } & no gas & 0.3 & 0.9991 & 0.2 & $0.9883-0.9960$ \\
\hline & & & & & no gas/HMI & 0.06 & 0.9990 & 0.05 & 0.9881-0.9981 \\
\hline
\end{tabular}

${ }^{a}$ Analytes where He and He/HMI were used. ICP OES: inductively coupled plasma optical emission spectrometry; ICP-MS: inductively coupled plasma mass spectrometry; EC: external standard calibration; MFC: multi-flow calibration; LOQ: limit of quantification; R²: determination coefficient; HMI: high matrix introduction; NA: not applicable once the element was not determined by this technique as shown in Table 2 .

1:2 for each of the CRM/RM analyzed. Tables 4 and 5 show the comparison between EC and MFC for ICP OES and ICP-MS determinations, respectively. Recoveries for the certified analytes in spinach leaves, polymer, and soil by ICP OES (Table 4), and spinach leaves, bovine liver, and polymer by ICP-MS (Table 5) are also shown.

In general, the best analyte recoveries were obtained with ICP OES using MFC (ranging from 78 to 109\%) for spinach leaves and soil compared to those calculated for EC (ranging from 54 to 86\%). Recoveries for the certified values of polymer using MFC were similar to those obtained with EC, demonstrating the effectiveness of the MFC strategy while analyzing complex-matrix samples by ICP OES. Furthermore, when EC was employed in ICP OES analysis, generally low recoveries were found, mainly for $\mathrm{Al}(72 \%)$ in spinach leaves and $\mathrm{Cu}(54 \%)$ and $\mathrm{Cd}(70 \%)$ in soil. These results indicate a critical matrix effect, which requires the adoption of an alternative strategy (e.g., calibration method) to overcome these non-spectral interferences and improve accuracy.

For $\mathrm{Al}$ determination in spinach leaves using MFC, generally adequate recovery $(82 \%)$ was obtained when the analyte concentration in the calibration standard solution had a sample/standard ratio of 1:2. For Cd in soil, recoveries of $80 \%$ were achieved when the sample/standard ratios of 1:0.5 and 1:2 were used. In most cases, adequate recoveries were obtained considering the concentration of the analytes in the calibration standard solution as sample/standard ratios $1: 0.5,1: 1$, and $1: 2$. Therefore, it is possible to apply any of the evaluated concentration ratios for elemental determinations by ICP OES and MFC as a calibration strategy without compromising the accuracy of the results. It is important to note here that MFC significantly contributes to improving accuracy when compared with EC, probably due to the plasma normalizing effect discussed earlier. However, a matrix-matching strategy such as standard additions and MEC may be required to improve further analyte recoveries (i.e., bring them within the $90-110 \%$ range) when analyzing samples subject to severe matrix effects. RSDs were less than or equal to $10 \%$ in all cases, except for $\mathrm{Cu}(18 \%)$ when EC was used as a calibration strategy.

For ICP-MS, the best analyte recoveries (ranging from 80 to $120 \%$ ) were obtained using MFC for spinach leaves 
Table 4. Evaluation of MFC used for $\mathrm{Al}, \mathrm{As}, \mathrm{Cd}, \mathrm{Cr}, \mathrm{Cu}, \mathrm{Mn}, \mathrm{Pb}$, and $\mathrm{Zn}$ determination by ICP OES considering the analytes concentration in the calibration standard solution as sample/standard ratios 1:0.5, 1:1, and 1:2. Determined values (mean \pm standard deviation, $\mathrm{n}=3$ ) and recoveries from the certified values in spinach leaves, soil and polymer

\begin{tabular}{|c|c|c|c|c|c|}
\hline \multirow{2}{*}{ Analyte } & \multicolumn{5}{|c|}{ Determined value (recovery / \%) / $\left(\mathrm{mg} \mathrm{kg}^{-1}\right)$} \\
\hline & Certified value & $\mathrm{EC}$ & MFC 0.5 & MFC 1.0 & MFC 2.0 \\
\hline & \multicolumn{5}{|c|}{ Spinach leaves (NIST 1570a) } \\
\hline Al & $310 \pm 11$ & $222 \pm 1(72)$ & $241 \pm 8(78)$ & $245 \pm 8(79)$ & $254 \pm 4(82)$ \\
\hline $\mathrm{Mn}$ & $76 \pm 2$ & $62.1 \pm 0.9(82)$ & $66.2 \pm 0.6(87)$ & $69.4 \pm 0.6(91)$ & $65.3 \pm 0.9(86)$ \\
\hline \multirow[t]{2}{*}{$\underline{\mathrm{Zn}}$} & $82 \pm 3$ & $65.9 \pm 0.5(80)$ & $74.2 \pm 0.3(90)$ & $77.8 \pm 0.4(95)$ & $74.6 \pm 0.1(91)$ \\
\hline & \multicolumn{5}{|c|}{ Soil (RM-Agro E2002a) } \\
\hline As & $59 \pm 7$ & $47 \pm 23(79)$ & $64 \pm 6(109)$ & $56 \pm 5(96)$ & $58 \pm 6(98)$ \\
\hline $\mathrm{Cd}$ & $94 \pm 11$ & $65 \pm 6(70)$ & $75 \pm 7(80)$ & $73 \pm 7(78)$ & $75 \pm 7(80)$ \\
\hline $\mathrm{Cr}$ & $120 \pm 30$ & $104 \pm 8(86)$ & $109 \pm 8(91)$ & $106 \pm 8(88)$ & $107 \pm 8(89)$ \\
\hline $\mathrm{Cu}$ & $9 \pm 4$ & $5 \pm 1(54)$ & $7 \pm 1(84)$ & $7 \pm 1(81)$ & $7 \pm 1(84)$ \\
\hline \multirow[t]{2}{*}{$\underline{\mathrm{Pb}}$} & $174 \pm 19$ & $166 \pm 15(96)$ & $178 \pm 16(102)$ & $169 \pm 15(97)$ & $173 \pm 16(100)$ \\
\hline & \multicolumn{5}{|c|}{ Polymer (ERM-EC681K) } \\
\hline As & $29 \pm 2$ & $23.9 \pm 0.5(82)$ & $30 \pm 1(104)$ & $24.4 \pm 0.9(84)$ & $32 \pm 1(110)$ \\
\hline $\mathrm{Cd}$ & $137 \pm 4$ & $127.3 \pm 0.01(93)$ & $134.5 \pm 0.2(98)$ & $131.4 \pm 0.3(96)$ & $138.5 \pm 0.3(101)$ \\
\hline $\mathrm{Pb}$ & $98 \pm 6$ & $90.4 \pm 0.1(92)$ & $94 \pm 4(96)$ & $91 \pm 3(93)$ & $101 \pm 4(103)$ \\
\hline
\end{tabular}

EC: external standard calibration; MFC: multi-flow calibration.

Table 5. Evaluation of MFC used for $\mathrm{As}, \mathrm{Cd}, \mathrm{Co}, \mathrm{Cu}, \mathrm{Hg}, \mathrm{Mo}, \mathrm{Mn}, \mathrm{Ni}, \mathrm{Se}, \mathrm{Sb}, \mathrm{Pb}$, and $\mathrm{V}$ determination by ICP-MS considering the analytes concentration in the calibration standard solution as sample/standard ratios 1:0.5, 1:1, and 1:2. Determined values (mean \pm standard deviation, $\mathrm{n}=3$ ) and recoveries from the certified values in spinach leaves, bovine liver and polymer

\begin{tabular}{|c|c|c|c|c|c|}
\hline \multirow{2}{*}{ Isotope } & \multicolumn{5}{|c|}{ Determined value (recovery / \%) / $\left(\mathrm{mg} \mathrm{kg}^{-1}\right)$} \\
\hline & Certified value & $\mathrm{EC}$ & MFC 0.5 & MFC 1.0 & MFC 2.0 \\
\hline & \multicolumn{5}{|c|}{ Spinach leaves (NIST 1570a) } \\
\hline${ }^{51} \mathrm{~V}$ & $0.57 \pm 0.03$ & $0.50 \pm 0.02(87)$ & $0.57 \pm 0.02(101)$ & $0.61 \pm 0.02(107)$ & $0.62 \pm 0.02(110)$ \\
\hline${ }^{58} \mathrm{Ni}$ & $2.4 \pm 0.1$ & $2.5 \pm 0.1(116)$ & $2.50 \pm 0.05(91)$ & $3.10 \pm 0.06(108)$ & $3.49 \pm 0.07(118)$ \\
\hline${ }^{59} \mathrm{Co}$ & $0.39 \pm 0.05$ & $0.22 \pm 0.02(55)$ & $0.37 \pm 0.01(95)$ & $0.40 \pm 0.01(102)$ & $0.40 \pm 0.01(103)$ \\
\hline${ }^{65} \mathrm{Cu}$ & $12.2 \pm 0.6$ & $10.3 \pm 0.4(85)$ & $11.3 \pm 0.2(92)$ & $11.7 \pm 0.3(96)$ & $12.1 \pm 0.3(99)$ \\
\hline${ }^{75} \mathrm{As}$ & $0.07 \pm 0.01$ & $0.09 \pm 0.03(127)$ & $<$ LOQ & $<$ LOQ & $<$ LOQ \\
\hline${ }^{78} \mathrm{Se}$ & $0.117 \pm 0.009$ & $<\mathrm{LOQ}$ & $<\mathrm{LOQ}$ & $<$ LOQ & $<$ LOQ \\
\hline \multirow[t]{2}{*}{${ }^{114} \mathrm{Cd}$} & $2.89 \pm 0.07$ & $2.32 \pm 0.08(81)$ & $2.62 \pm 0.05(91)$ & $2.71 \pm 0.05(94)$ & $2.78 \pm 0.05(97)$ \\
\hline & \multicolumn{5}{|c|}{ Bovine liver (RM-Agro E3001a) } \\
\hline${ }^{55} \mathrm{Mn}$ & $8 \pm 1$ & $6.9 \pm 0.06(92)$ & $7.75 \pm 0.09(102)$ & $7.93 \pm 0.09(104)$ & $8.04 \pm 0.09(105)$ \\
\hline${ }^{59} \mathrm{Co}$ & $0.32 \pm 0.05$ & $0.26 \pm 0.01(81)$ & $0.340 \pm 0.006(87)$ & $0.352 \pm 0.006(98)$ & $0.340 \pm 0.006(91)$ \\
\hline${ }^{78} \mathrm{Se}$ & $0.7 \pm 0.1$ & $0.5 \pm 0.2(75)$ & $0.64 \pm 0.04(95)$ & $0.75 \pm 0.06(112)$ & $0.76 \pm 0.06(113)$ \\
\hline${ }^{98} \mathrm{Mo}$ & $4.1 \pm 0.1$ & $3.13 \pm 0.09(77)$ & $3.32 \pm 0.08(81)$ & $3.6 \pm 0.09(88)$ & $3.49 \pm 0.09(90)$ \\
\hline \multirow[t]{2}{*}{${ }^{114} \mathrm{Cd}$} & $0.104 \pm 0.02$ & $0.059 \pm 0.003(57)$ & $0.092 \pm 0.005(106)$ & $0.103 \pm 0.006(110)$ & $0.096 \pm 0.005(106)$ \\
\hline & \multicolumn{5}{|c|}{ Polymer (ERM-EC680K) } \\
\hline${ }^{75} \mathrm{As}$ & $4.1 \pm 0.5$ & $3.6 \pm 0.6(89)$ & $3.1 \pm 0.2(76)$ & $3.3 \pm 0.23(82)$ & $3.3 \pm 0.3(81)$ \\
\hline${ }^{114} \mathrm{Cd}$ & $20 \pm 1$ & $24.2 \pm 0.1(121)$ & $20.8 \pm 0.6(104)$ & $21 \pm 1(105)$ & $20.8 \pm 0.8(104)$ \\
\hline${ }^{123} \mathrm{Sb}$ & $10 \pm 2$ & $15 \pm 3(149)$ & $9.9 \pm 0.5(99)$ & $11.2 \pm 0.7(111)$ & $10.6 \pm 0.6(105)$ \\
\hline${ }^{202} \mathrm{Hg}$ & $4.6 \pm 0.2$ & $4 \pm 3(99)$ & $4.4 \pm 0.08(96)$ & $5.1 \pm 0.2(110)$ & $5.4 \pm 0.4(117)$ \\
\hline${ }^{208} \mathrm{~Pb}$ & $13.6 \pm 0.5$ & $13 \pm 9(99)$ & $10.2 \pm 0.6(75)$ & $12.9 \pm 0.5(95)$ & $12.9 \pm 0.6(95)$ \\
\hline
\end{tabular}

EC: external standard calibration; MFC: multi-flow calibration; LOQ: limit of quantification. 
and bovine liver CRMs. For polymer, the most complex matrix evaluated, the recoveries obtained for ${ }^{114} \mathrm{Cd}^{+}$and ${ }^{123} \mathrm{Sb}^{+}$with MFC were between 99 and $111 \%$ and for the other analytes, the recoveries were similar to those obtained with EC. Moreover, high values of RSD were observed for all analytes (except $\mathrm{Cd}$ ) for $\mathrm{EC}$, which is effectively corrected using MFC (RSD $<10 \%)$. According to Williams et al.., ${ }^{19}$ MFC performed better in MIP OES analysis when the analyte concentration in the sample was within an order of magnitude of that of the calibration standard solution.

In the present study, satisfactory recoveries were obtained for the evaluated sample/standard ratios of 1:0.5 and 1:2. It is important to mention that the analyte concentration in the sample is calculated from equation 1 , in which is directly proportional to $\mathrm{C}_{\text {standard, }}$ therefore this concentration cannot be very low or very high compared to analyte concentration in the sample. Another important aspect is about analysis of sample with unknown analyte concentration, which occur frequently in routine analysis; in this case we must estimate the analyte concentration of these samples and then decide the value of $\mathrm{C}_{\text {standard }}$. This procedure is similar to $\mathrm{EC}$ for analysis of a sample with unknown analyte concentration. Thus, the MFC method may be readily employed in the routine analysis, as elements in different samples can be present in a wide range of concentrations. Similar to other calibration methods, in which the analyst must ensure concentrations in the sample are within the linear dynamic range for a given analyte, sample dilution or adequation of the calibration standard solution concentration to that of the sample may be required when applying MFC.

It is important to consider that for the MFC method, the sample throughput of the instrumental measurements is affected because it requires, for the most ICPs' software, a new method for obtaining the analytical signals in each Q condition. However, Williams et al. ${ }^{19}$ highlight that to compare the sample throughput between MFC and EC is necessary to consider also the time spent to prepare the calibration standard solutions, because this affects significantly the sample throughput of the method. Depending on the sample amount, the time spent to prepare the solutions can compensate the measurement time and, in this case, the sample throughput of the MFC method may be comparable to EC.

As shown in Table 3, the LOQs for As and Se using EC $\left(0.07\right.$ and $\left.0.3 \mathrm{mg} \mathrm{kg}^{-1}\right)$ and MFC $\left(0.3\right.$ and $\left.0.2 \mathrm{mg} \mathrm{kg}^{-1}\right)$ were higher than the certified values for these analytes in the spinach leaves digest ( 0.070 and $0.12 \mathrm{mg} \mathrm{kg}^{-1}$, respectively). However, when using HMI, a dilution factor 10 -fold lower than without HMI was employed, which resulted in better LOQs for both EC and MFC (see Table 3). Using
HMI, the recoveries (and RSDs) obtained for As and Se were $85(10) \%$ and $109(15) \%$ for EC, and 105 (7)\% and 104 (2)\% for MFC (with an analyte concentration in the calibration standard solution at a sample/standard ratio of 1:1).

The HMI mode implies that the sample aerosol was diluted with $\operatorname{Ar}(60 \%$ of the nebulization gas flow comes from the HMI channel). ${ }^{24}$ According to the results shown, the use of HMI with MFC has no effect on sample processing during the analyses and no adverse effect on the energy of the plasma. Besides, to allow for less sample dilution and consequently higher analyte concentrations in the sample digest, aerosol dilution also minimizes potential contamination associated with manual dilution. Finally, it also reduces the volume of waste generated compared with conventional liquid dilution.

\section{TFC method performance}

From the MFC results obtained, it can be stated that MFC is an effective calibration strategy for elemental determination by ICP OES and ICP-MS, with results comparable to or better than those obtained using EC. However, considering some studies in which one addition point has been used to build a calibration curve, ${ }^{17,18,25-27}$ higher or similar precision were obtained when compared to multipoint calibrations. In this case, we evaluated the use of only two nebulization gas flow rates (2-Q) for both techniques. This strategy represents an economy in $\mathrm{Ar}$ consumption and improves the sample throughput. Figure 2 shows the linear models obtained using two nebulization gas flow rates $\left(0.3\right.$ and $\left.0.6 \mathrm{~L} \mathrm{~min}^{-1}\right)$ in ICP OES and $(0.4$ and $0.8 \mathrm{~L} \mathrm{~min}^{-1}$ ) in ICP-MS determinations.

On the other hand, when only two flow rates are used to calculate a linear model, it is mandatory to perform an $F$-test to evaluate the significance of all models. ${ }^{28} \mathrm{In}$ this situation, $F_{\text {calculated }} / F_{\text {tabulated }}$ ratio was calculated in all cases. The $F_{\text {calculated }}$ value is related to mean of the square of regression (MQR) and mean of the square of residues (MQr), and, if the ratio $\geq 10$, the variance from regression (MQR) is statistically and consistently different from the variance from the residue (MQr). In this case, the model can be considered linear. The ratios found for all samples and analytes (except for $\mathrm{Cu}$ ) ranged from 13 to 19650, which means that with two nebulization gas flow rates, it is possible to reach significative models. Furthermore, the use of only two nebulization gas flow does not change the accuracy of the results (recoveries ranged from 80 to $110 \%$ for ICP OES and from 81 to $102 \%$ for ICP-MS), which suggests that the TFC strategy can be also applied, resulting in a method with high analytical frequency. 

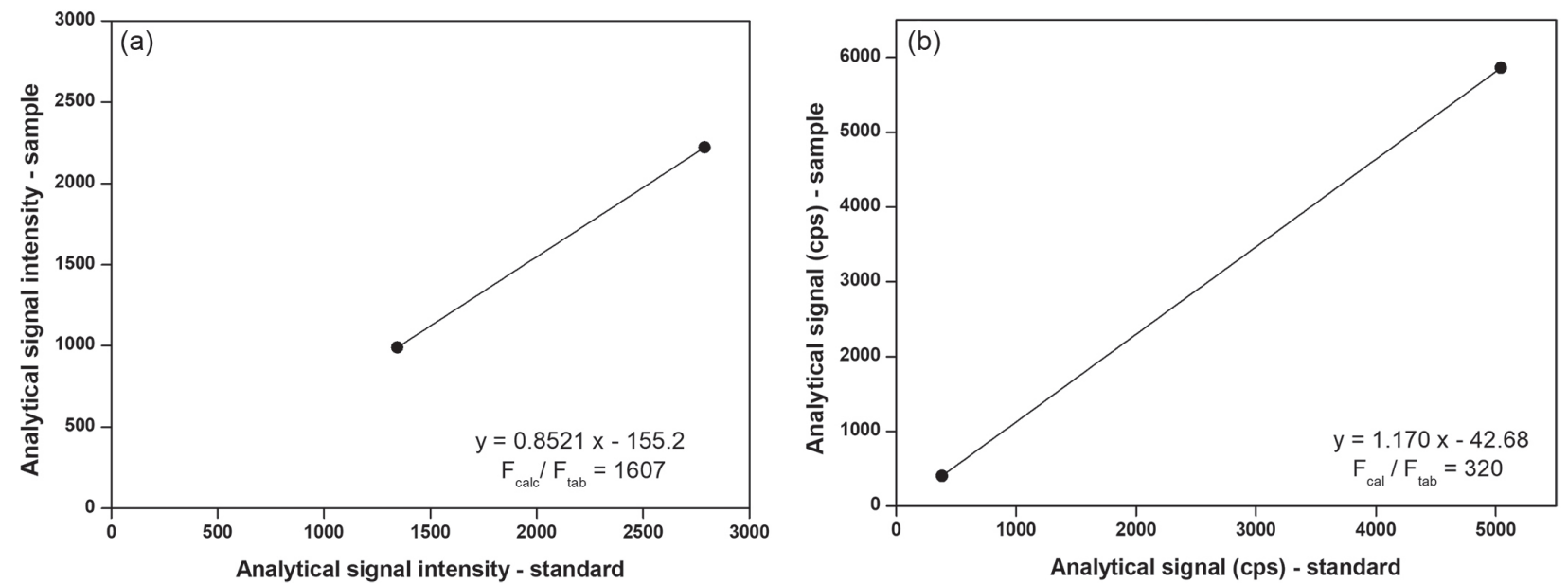

Figure 2. Multi-flow linear models using only two nebulization gas flow rates for the analytes concentration in the calibration standard solution as sample/ standard ratio 1:1 for determination of (a) Cd in soil RM-Agro E2002a by ICP OES, and (b) V in spinach leaves CRM (NIST 1570a) by ICP-MS.

\section{Conclusions}

Multi-flow and two-flow calibrations were evaluated as strategies to improve the accuracy of elemental determination by ICP OES and ICP-MS for several matrices. The methods described here proved to be useful to minimize matrix effects in ICP-based analyses, using a single calibration standard. Different nebulization gas flow rates (which result in different plasma conditions) were used for data acquisition in both ICP OES and ICP-MS, and in all cases, the concentration of the analyte in the calibration standard solution did not change the accuracy of the results for MFC. The MFC results were compared to values obtained for EC and, in most cases, the best recoveries for all reference materials and certified reference materials evaluated were obtained when using the former, with RSDs lower than $10 \%$ for both ICP-based methods. On the other hand, changes in the nebulization gas flow rate can lead to high background signals in ICP OES, resulting in higher LODs and LOQs for MFC compared to EC.

To ensure adequate accuracy in As and Se determination in spinach leaves by ICP-MS, the HMI mode and He in the collision/reaction cell were employed, which allowed for less sample dilution before the analysis and lower LODs. It is worth noting that, even with this additional gas flow, no change in MFC performance was observed. Another aspect discussed in this study is the successful possibility of using only two nebulization gas flow rates to build linear models for calibration. The $F_{\text {calculated }} / F_{\text {tabulated }}$ ratios calculated were $\geq 10$ (except for $\mathrm{Cu}$ ), which indicates good significance for the TFC regression models, and no adverse results were obtained when accuracy of the results were evaluated.

\section{Acknowledgments}

This work was supported by the Coordenação de Aperfeiçoamento de Pessoal de Nível Superior, Brazil (CAPES/PNPD-National Postdoctoral Program, Federal University of São Carlos) finance code 001; Research Foundation of São Paulo (FAPESP, grant numbers 2016/17304-0, 2018/26145-9, and 2019/24223-5); and to the Conselho Nacional de Desenvolvimento Científico e Tecnológico ( $\mathrm{CNPq}$ ) for financial support (projects 401074/2014-5, 305637/2015-0, and grant numbers 153125/2016-0, 308178/2018-1 and 141634/2017-0). Instrumental support provided by Milestone is gratefully acknowledged. This study was also financed in part by the National Bank for Economic and Social Development (BNDES-2117020010607). This is a contribution of the National Institute of Advanced Analytical Science and Technology (INCTAA).

\section{Author Contributions}

Raquel C. Machado, Ana Beatriz S. Silva, Daniel F. Andrade and Fernanda C. Pinheiro were responsible for conceptualization, methodology, validation, formal analysis, investigation, writing-original draft, writing-review and editing and visualization; Charles B. Williams was responsible for conceptualization, writing-original draft and visualization; George L. Donati for conceptualization, writing-original draft, writing-review and editing and visualization; Ana Rita A. Nogueira for writing-original draft, writing-review and editing, visualization, funding acquisition, project administration and resources; Edenir R. PereiraFilho for conceptualization, investigation, writing-original draft, writing-review and editing, visualization, funding acquisition, project administration, resources and supervision. 


\section{References}

1. Pröfrock, D.; Prange, A.; Appl. Spectrosc. 2012, 66, 843.

2. Donati, G. L.; Amais, R. S.; Williams, C. B.; J. Anal. At. Spectrom. 2017, 32, 1283.

3. Lum, T.; Leung, K. S.; J. Anal. At. Spectrom. 2016, 31, 1078.

4. Todolí, J. L.; Gras, L.; Hernandis, V.; Mora, J.; J. Anal. At. Spectrom. 2002, 17, 142.

5. Laborda, F.; Górriz, M. P.; Bolea, E.; Castillo, J. R.; Spectrochim. Acta, Part B 2006, 61, 433.

6. Sakata, K.; Kawabat, K.; Spectrochim. Acta, Part B 1994, 49, 1027.

7. Pereira, C. D.; Garcia, E. E.; Silva, F. V.; Nogueira, A. R. A.; Nobrega, J. A.; J. Anal. At. Spectrom. 2010, 25, 1763.

8. George, C.; Chan, Y.; Chan, W. T.; Spectrochim. Acta, Part B 2003, 58, 1301.

9. Grotti, M.; Leardi, R.; Frache, R.; Spectrochim. Acta, Part B 2002, 57, 1915.

10. Leclercq, A.; Nonell, A.; Todolí, J. L.; Bresson, C.; Vio, L.; Vercouter, T.; Chartier, F.; Anal. Chim. Acta 2015, 23, 33.

11. Agatemor, C.; Beauchemin, D.; Anal. Chim. Acta 2011, 706, 66.

12. Todolí, J. L.; Mermet, J. M.; Encyclopedia of Analytical Chemistry; Meyers, R. A., ed.; Wiley: Chichester, 2011.

13. Jones, W. B.; Donati, G. L.; Calloway Jr., C. P.; Jones, B. T.; Anal. Chem. 2015, 87, 2321.

14. Virgilio, A.; Gonçalves, D. A.; McSweeney, T.; Gomes Neto, J. A.; Nóbrega, J. A.; Donati, G. L.; Anal. Chim. Acta 2017, 982, 31.

15. Virgilio, A.; Nóbrega, J. A.; Donati, G. L.; Anal. Bioanal. Chem. 2018, 410, 1157.
16. Williams, C. B.; Donati, G. L.; J. Anal. At. Spectrom. 2018, 33 , 762.

17. Pinheiro, F. C.; Barros, A. I.; Nóbrega, J. A.; Microchem. J. 2019, 146, 948.

18. Pinheiro, F. C.; Babos, D. V.; Barros, A. I.; Pereira-Filho, E. R.; Nóbrega, J. A.; J. Pharm. Biomed. Anal. 2019, 174, 471.

19. Williams, C. B.; Jones, B. T.; Donati, G. L.; J. Anal. At. Spectrom. 2019, 34, 1191.

20. Bianchi, S. R.; Peixoto, A. M. J.; Souza, G. B.; Tullio, R. R.; Nogueira, A. R. A.; J. Phys.: Conf. Ser. 2016, 733, 012006.

21. Nogueira, A. R. A.; Souza, G. B.; Bossu, C. M.; Bianchi, S. R.; Verhalen, T. R.; Silva, P. T.; Peixoto, A. A. J.; Silva, C. S.; J. Phys.: Conf. Ser. 2016, 733, 012005.

22. Thomsen, V.; Schatzlein, D.; Mercuro, D.; Spectroscopy 2003 , $18,112$.

23. Thomas, R. J.; Measuring Elemental Impurities in Pharmaceuticals: A Practical Guide, $1^{\text {st }}$ ed.; CRC Press: Boca Raton, New York, 2018.

24. Barros, A. I.; Pinheiro, F. C.; Amaral, C. D. B.; Lorençatto, R.; Nóbrega, J. A.; Talanta 2018, 178, 805.

25. Brown, R. J. C.; Gillam, T. P. S.; Anal. Chim. Acta 2012, 716, 108.

26. Babos, D. V.; Barros, A. I.; Nóbrega, J. A.; Pereira-Filho, E. R.; Spectrochim. Acta, Part B 2019, 155, 90.

27. Castro, J. P.; Babos, D. V.; Pereira-Filho, E. R.; Talanta 2020, 208, 120443.

28. Christian, G. D.; Dasgupta, P. K.; Schug, K. A.; Analytical Chemistry, $7^{\text {th }}$ ed.; Wiley: New Jersey, United States, 2013.

Submitted: September 2, 2020 Published online: December 2, 2020 